\title{
Article \\ Uncovering the Bioactive Potential of a Cyanobacterial Natural Products Library Aided by Untargeted Metabolomics
}

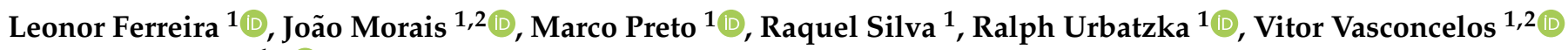 \\ and Mariana Reis $1, *$ (D) \\ 1 CIIMAR/CIMAR, Interdisciplinary Centre of Marine and Environmental Research, Terminal de Cruzeiros do \\ Porto de Leixões, University of Porto, 4450-208 Matosinhos, Portugal; Iferreira@ciimar.up.pt (L.F.); \\ jmorais@ciimar.up.pt (J.M.); mpreto@ciimar.up.pt (M.P.); rssilva@ciimar.up.pt (R.S.); \\ rurbatzka@ciimar.up.pt (R.U.); vmvascon@fc.up.pt (V.V.) \\ 2 Departamento de Biologia, Faculdade de Ciências, Universidade do Porto, Rua do Campo Alegre, \\ Edifício FC4, 4169-007 Porto, Portugal \\ * Correspondence: mreis@ciimar.up.pt
}

check for updates

Citation: Ferreira, L.; Morais, J.; Preto, M.; Silva, R.; Urbatzka, R.; Vasconcelos, V.; Reis, M. Uncovering the Bioactive Potential of a Cyanobacterial Natural Products Library Aided by Untargeted Metabolomics. Mar. Drugs 2021, 19, 633. https://doi.org/10.3390/ md19110633

Academic Editor: Bill J. Baker

Received: 15 October 2021

Accepted: 10 November 2021

Published: 12 November 2021

Publisher's Note: MDPI stays neutral with regard to jurisdictional claims in published maps and institutional affiliations.

Copyright: (c) 2021 by the authors. Licensee MDPI, Basel, Switzerland. This article is an open access article distributed under the terms and conditions of the Creative Commons Attribution (CC BY) license (https:// creativecommons.org/licenses/by/ $4.0 /)$.

\begin{abstract}
The Blue Biotechnology and Ecotoxicology Culture Collection (LEGE-CC) holds a vast number of cyanobacteria whose chemical richness is still largely unknown. To expedite its bioactivity screening we developed a natural products library. Sixty strains and four environmental samples were chromatographed, using a semiautomatic HPLC system, yielding 512 fractions that were tested for their cytotoxic activity against 2D and 3D models of human colon carcinoma (HCT 116), and non-cancerous cell line hCMEC/D3. Six fractions showed high cytotoxicity against 2D and 3D cell models (group A), and six other fractions were selected by their effects on 3D cells (group B). The metabolome of each group was organized and characterized using the MolNetEnhancer workflow, and its processing with MetaboAnalyst allowed discrimination of the mass features with the highest fold change, and thus the ones that might be bioactive. Of those, mass features without precedented identification were mostly found in group A, indicating seven possible novel bioactive molecules, alongside in silico putative annotation of five cytotoxic compounds. Manual dereplication of group $\mathrm{B}$ tentatively identified nine pheophytin and pheophorbide derivatives. Our approach enabled the selection of 7 out of 60 cyanobacterial strains for anticancer drug discovery, providing new data concerning the chemical composition of these cyanobacteria.
\end{abstract}

Keywords: natural products library; cyanobacteria; cytotoxicity; 3D spheroids; untargeted metabolomics; MetaboAnalyst; GNPS

\section{Introduction}

Natural products continue to inspire many drug discovery programs; as such, more than sixty percent of the approved drugs comprise natural products, their synthetic derivatives, and their pharmacophore-inspired drugs [1]. Cyanobacteria have been regarded as one of the most promising groups of organisms capable of producing metabolites with pharmaceutical applications [2]. Since the 1970s, more than 1630 unique cyanobacterial compounds have been described [3], mainly belonging to the classes of non-ribosomal peptides (NRPs), ribosomally synthesized and post translationally-modified peptides (RiPPs), polyketides (PKs), and the hybrid NRPs/PKs [3,4]. These hybrid molecules contribute to the diversity of structural motifs found in cyanobacterial compounds. In addition, other classes of secondary metabolites have also been isolated from cyanobacteria as alkaloids, fatty acids, terpenes, and UV-protectant pigments [3,4]. Among the reported bioactivities, a great deal of studies have focused on the characterization of the cytotoxic and anticancer activity of cyanobacterial metabolites; among those, dolastatin 10 , a tubulin polymerization inhibitor, is the most well-known [3,5]. Its synthetic derivatives monomethylauristatins yielded four approved antibody drug conjugates: Adcetris (2011) and Polivy (2019), used 
for the treatment of lymphoma; Padcev (2019), applied for the treatment of urinary tract cancers; and Blenrep (2020), for the treatment of relapsed and refractory multiple myeloma [6].

The Blue Biotechnology and Ecotoxicology Culture Collection (LEGE-CC, http:/ / www.ciimar.up.pt/legecc/), hosted at CIIMAR (Matosinhos, Portugal), is a unique biological resource that hosts more than 700 strains of cyanobacteria, covering a wide range of geographical habitats. These are mainly represented by marine and freshwater water systems, but there are also representative strains from brackish, hypersaline, and terrestrial environments [7]. Regardless this biodiversity, this natural resource is still underexplored in terms of the discovery of new chemical entities. Our bioactivity-guided screening endeavors have delivered compounds such as lactylates of chlorinated fatty acids (chlorosphaerolactylates A-D) with antimicrobial effects [8]; chlorophyll derivatives with lipid reducing activity [9]; and compounds with anticancer activity, such as oxadiazine Nocuolin A [10], alkylresorcinol hierridin B [11], and the NRPs portoamides A-B [12] that also proved to have promising antifouling activity [13]. Despite these successes, our classic approach for cyanobacterial natural products discovery is often time consuming, originates false positives (synergistic effects), and ends frequently in the unsuccessful isolation of the active components due to their low concentrations. To overcome these problems and encompass the growing number of new cyanobacterial strains entering LEGE-CC, a new strategy for bioactivity screening is needed in order to accelerate our drug discovery process. In this study, we describe the generation of a natural products library and its assessment for potential cytotoxic activity. An untargeted metabolomics approach was used to discover and highlight the putative bioactive molecules.

\section{Results and Discussion}

\subsection{Cyanobacterial Natural Products Library (LEGE-NPL)}

In the last 10 years, LEGE-CC has had a significant increase in the number of deposited strains; nevertheless, its associated drug discovery has not been able to keep the same pace. As a possible solution for this problem, we designed a methodology for a cyanobacterial natural products library (LEGE-NPL). To test this approach, 60 cyanobacterial strains and 4 environmental samples were used (Table S1). The selected strains belong to different cyanobacterial orders following the classification of Komárek et al. [14]: Synechococcales $(46 \%)$, Oscillatoriales (27\%), Nostocales (15\%), Chroococcales (10\%), and Pleurocapsales $(2 \%)$, representing the phylogenetic diversity of LEGE-CC (Figure 1). In addition, these orders have been considered to be a good asset for secondary metabolites research due to the richness in biosynthetic gene clusters found in their genomes $[3,5,15]$.

The LEGE-NPL was designed to have a solid inventory (MeOH extracts) and a liquid inventory of fractions. The raw material that supplied the solid inventory was derived from $4 \mathrm{~L}$ cultures of cyanobacteria that yielded on average $2.57 \mathrm{~g}$ of dry weight (Figure S1). $\mathrm{MeOH}$ was chosen as solvent to produce the solid library because of its the ability to extract components with different polarities; previous results using sequential extraction did not show advantage of using different solvents over the single use of $\mathrm{MeOH}$ [9]. The average yield of extraction was $15.50 \%$ of the lyophilized biomass (Figure S1). The liquid inventory, constituted by eight fractions (denominated from $\mathrm{A}$ to $\mathrm{H}$ ) derived from each $\mathrm{MeOH}$ extract, was designed to be fully compatible with a 96-well plate format for bioactivity screening. It was produced in semiautonomous fashion using a HPLC system coupled to an automatic injector, PDA detector, and an automatic fraction collector. Hence, the $64 \mathrm{MeOH}$ extracts were separated on a $\mathrm{C} 8$ column using a gradient of $\mathrm{H}_{2} \mathrm{O} / \mathrm{MeCN}$, yielding a total of 512 fractions. The total run time, including gradient recovery, was $20 \mathrm{~min}$ per strain. These chromatographic conditions were optimized to ensure a good mass separation between all eight fractions that were estimated to have $2.50 \mathrm{mg}$. These plates were dried using a centrifugal evaporation system, resuspended in DMSO, and stored in 96-deep well plates as mother plates. The choice of the stationary phase considered the recent woks of the National Cancer Institute Program for Natural Products Discovery that 
indicated C8 as a preferred stationary-phase over the classical C18 or silica due to a better separation between lipophilic and medium polarity compounds [16].

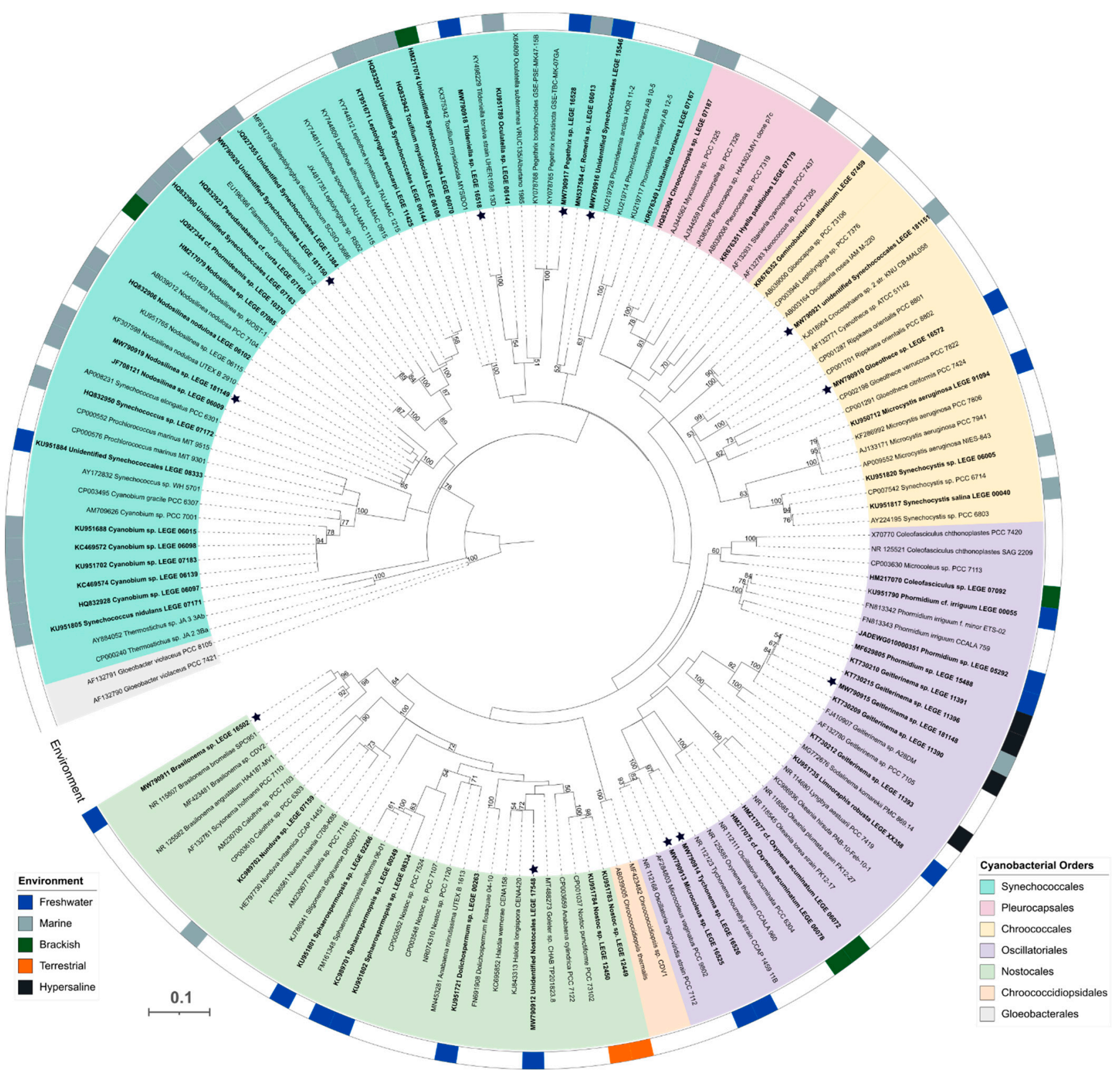

Figure 1. Maximum likelihood phylogenetic tree based on 146 partial 16S rRNA gene sequences of cyanobacteria. Gloeobacter violaceus PCC 7421 and G. violaceus PCC 8105 were used as outgroup. LEGE-CC strains used in this work are indicated in bold. The different color segments represent strain placement at order level following Komárek et al. [14]. Different colored strips around the tree represent the environment from where strains were isolated. Bootstrap values over 50\% are indicated at the nodes. Black stars represent the strains whose sequences were obtained in this work. 


\subsection{Bioactivity Screening}

Another aim of this work was to use cancer spheroids in routine screenings of LEGENPL. The cancer spheroids are characterized by a hypoxic core with quiescent cells and a prolific outer shell, and thus, they more accurately simulate the tumor microenvironment than 2D cultures. Due to this complexity, 3D culture systems are considered to be less prone to showing effects of unspecific activities or to overestimate the activity of compounds, increasing the chances of finding potent lead compounds [17].

The colon carcinoma cell line HCT 116 was chosen due to its ability to form uniform spheroids using the liquid-overlay technique, and because it had already been used in confirmation assays for cyanobacterial compounds [10,18]. Moreover, the assays using HCT 116 cells were used to compare the 2D versus 3D hit selection. The endpoints and readout techniques were adjusted accordingly to the nature of the cell culture system. For 2D cell cultures, cell viability was assessed by the standard MTT assay after a $48 \mathrm{~h}$ incubation period. This colorimetric assay was not suitable to measure cell viability in spheroids (Figure S2). This was verified mainly due to the poor diffusion of the dye, which can be attributed to the 3D matrices and tight cell-cell junctions present in the multilayer cell spheroids [19], resulting in low differentiation of the metabolic activity of the cells. Thus, for 3D cell cultures, cell viability was measured using the acid phosphatase assay after $96 \mathrm{~h}$ (longer exposure times in 3D cell cultures increase the sensitivity of the assay and reduce the false negative hits [19]). Moreover, to test the hypothesis that our methodology would be able to detect active compounds in fractionated extracts, the strain Phormidium sp. LEGE 05292 was included in the study set (as a positive control). This strain is known to produce the cytotoxic peptides portoamides A and B in a proportion of 3:1 [12]. This mixture presented $\mathrm{IC}_{50}$ values of $3.38 \mu \mathrm{M}$ and $12.67 \mu \mathrm{M}$, respectively, to monolayer cultures and multicellular spheroids of HCT 116 cells. These results indicated that an approximate 4-fold higher concentration is needed to induce cytotoxicity in spheroids [18].

The 512 fractions of LEGE-NPL $\left(25 \mu \mathrm{g} \mathrm{mL}{ }^{-1}\right)$ were screened for their cytotoxic effect on the colon carcinoma cells (2D HCT 116, 3D HCT 116) and a non-carcinogenic cell line hCMEC/D3 (Figure 2). The non-carcinogenic cell line was not used to select hits; instead it was used to test if the fractions exerted a generalized cytotoxicity or if they had selectivity towards cancer cells. The results were expressed as the percentage of cell viability normalized to the solvent control. To characterize the dynamic range of the assays, the $Z^{\prime}$ factor was calculated using the positive (LEGE 05292_C) and solvent control (DMSO) data. The $Z^{\prime}$ scores of $0.64-0.83$ indicated that the mean and standard deviation of the controls were well separated [20], and thus the criteria to select positive hits was established as the mean viability of LEGE 05292_C plus three times its standard

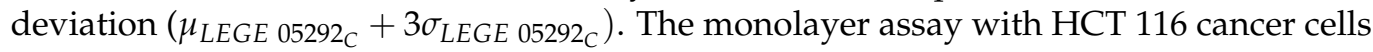
had a hit rate of $0.4 \%$, selecting the active fractions LEGE 181150_D and LEGE 17548_C (Figure 2). For the 3D HCT 116 cell assay, 11 active fractions were selected (2.1\% hit rate) that correspond to one environmental sample and eight cyanobacterial strains (Figure 2). Contrary to what we expected, a higher hit rate was observed for the 3D spheroids than for the monolayer counterpart. Hence, the cell viability data from the three cell models was correlated in a 3D scatter plot to disclose any bioactivity tendency. As such, two bioactive groups could be recognized (Figure 3). Group A contains 5 fractions that present strong cytotoxicity towards the cancer and non-cancer cells (Table 1), whereas group B contains fractions selected for their activity in HCT 116 spheroids despite the moderate activity in the other monolayer assays. In light of these results, the fractions from both groups were selected for metabolomics studies in order to discover the potential cytotoxic compounds. 


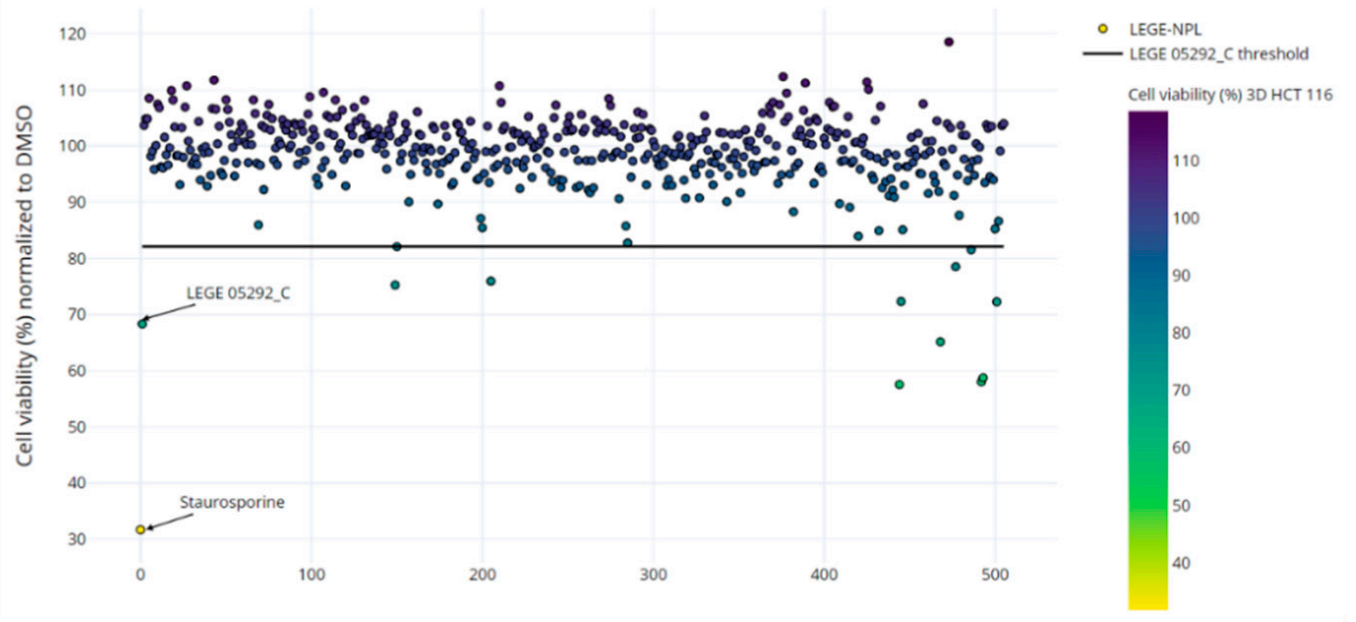

2D HCT 116

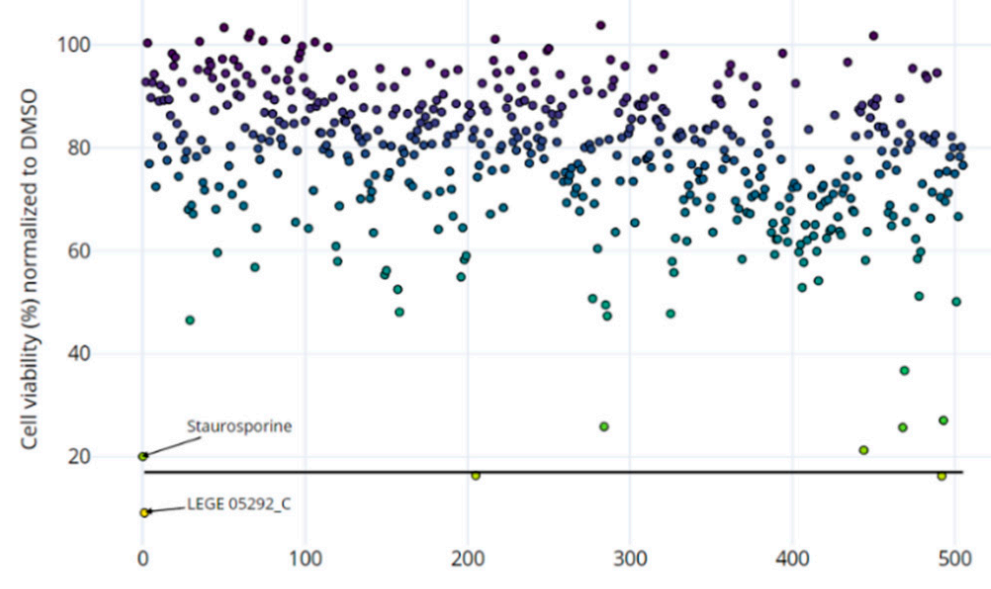

2D hCMEC/D3
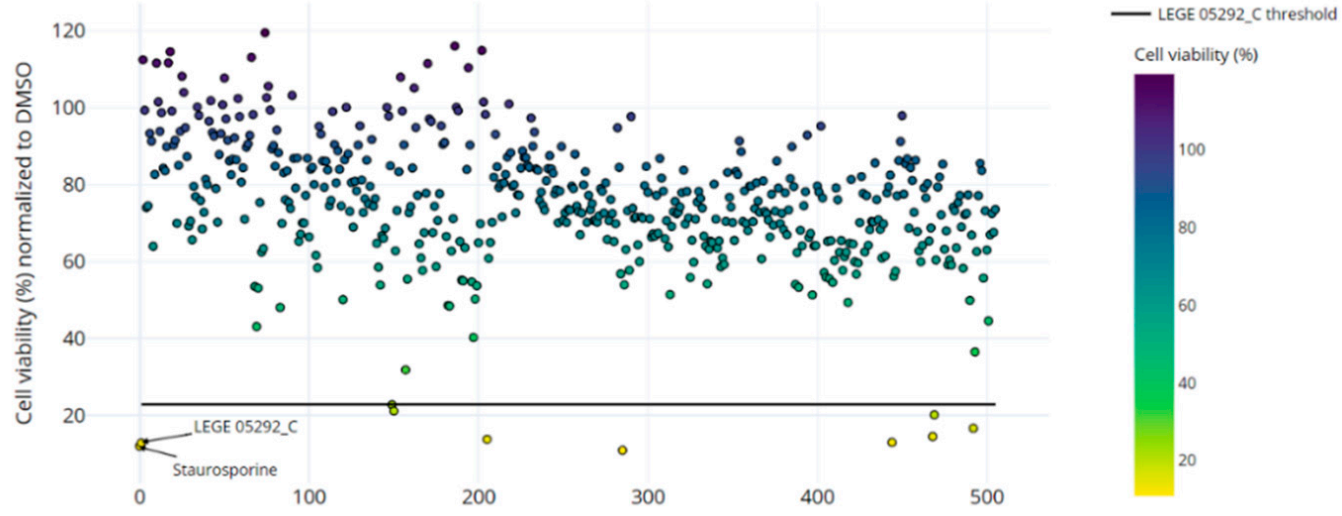

Figure 2. Cytotoxicity screening of 512 fractions of LEGE-NPL (at $25 \mu \mathrm{g} \mathrm{mL}^{-1}$ ) against 3D cell spheroids of HCT 116 cells, 2D HCT 116 cells, and hCMEC/D3. The percentage of cell viability was normalized to DMSO. The threshold for selection of positive hits was defined as mean viability of the cytotoxic faction LEGE 05292_C plus three times its standard deviation. All the assays were done in triplicate. 


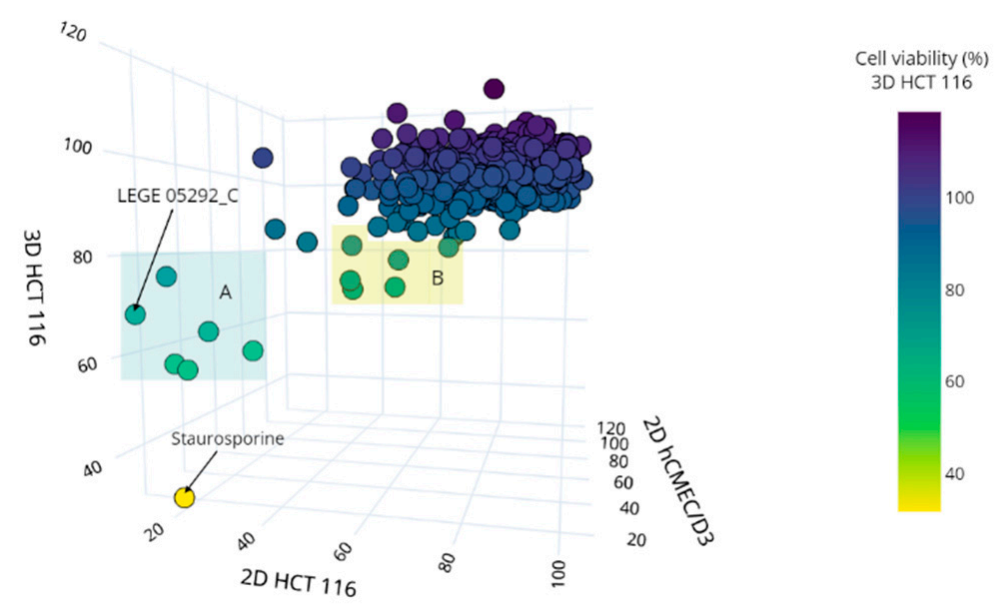

Figure 3. 3D plot correlation of the cytotoxic profile of 512 fractions on the different cell models (3D HCT 116, 2D HCT 116, and hCMEC/D3). The $x, y$, and $z$ axis represent the percentage of cell viability (normalized to DMSO). Two groups were defined based on the cytotoxic profile: group A and group B.

Table 1. Cytotoxic profile of the selected fractions of group A, B, and C.

\begin{tabular}{|c|c|c|c|c|}
\hline & \multirow{2}{*}{ Fractions } & \multicolumn{3}{|c|}{ Cell Viability (\%) } \\
\hline & & 3D HCT 116 & 2D HCT 116 & 2D hCMEC/D3 \\
\hline \multirow{6}{*}{ Group A } & LEGE 16572_C & $57.54 \pm 20.74$ & $21.30 \pm 8.79$ & $12.97 \pm 5.14$ \\
\hline & LEGE 17548_C & $58.05 \pm 11.10$ & $16.33 \pm 8.50$ & $16.67 \pm 11.84$ \\
\hline & LEGE 17548_D & $58.74 \pm 13.40$ & $27.08 \pm 17.23$ & $36.52 \pm 16.23$ \\
\hline & LEGE 15488_C & $65.16 \pm 10.30$ & $25.69 \pm 21.02$ & $14.51 \pm 8.65$ \\
\hline & LEGE 181150_D & $75.95 \pm 4.25$ & $16.40 \pm 3.26$ & $13.80 \pm 3.14$ \\
\hline & LEGE 05292_C & $68.32 \pm 4.60$ & $9.13 \pm 2.64$ & $12.83 \pm 3.35$ \\
\hline \multirow{6}{*}{ Group B } & LEGE XX358_D & $72.28 \pm 16.86$ & $50.11 \pm 20.43$ & $44.60 \pm 14.66$ \\
\hline & LEGE 16572_D & $72.34 \pm 6.05$ & $58.15 \pm 23.40$ & $56.18 \pm 19.94$ \\
\hline & JM1 Amb_D & $75.25 \pm 7.14$ & $55.30 \pm 3.11$ & $22.77 \pm 5.59$ \\
\hline & LEGE 15546_D & $78.51 \pm 7.16$ & $58.44 \pm 18.34$ & $59.17 \pm 15.65$ \\
\hline & LEGE 16502_E & $81.53 \pm 13.30$ & $71.38 \pm 13.24$ & $58.29 \pm 7.41$ \\
\hline & JM1 Amb_E & $82.07 \pm 3.02$ & $56.16 \pm 12.80$ & $21.15 \pm 5.76$ \\
\hline \multirow{12}{*}{ Group C } & JM5_amb_D & $90.07 \pm 1.24$ & $52.49 \pm 5.34$ & $31.85 \pm 4.39$ \\
\hline & JM5_amb_E & $94.92 \pm 5.66$ & $48.11 \pm 12.12$ & $55.44 \pm 7.66$ \\
\hline & LEGE 06078_D & $99.29 \pm 7.89$ & $46.51 \pm 12.42$ & $69.21 \pm 15.63$ \\
\hline & LEGE 07092_D & $94.96 \pm 6.94$ & $47.77 \pm 3.62$ & $55.86 \pm 3.63$ \\
\hline & LEGE 07167_C & $85.76 \pm 2.54$ & $25.86 \pm 1.36$ & $56.83 \pm 4.00$ \\
\hline & LEGE 07167_D & $82.74 \pm 3.25$ & $49.51 \pm 1.90$ & $10.93 \pm 2.87$ \\
\hline & LEGE 07167_E & $99.70 \pm 4.71$ & $47.34 \pm 1.59$ & $53.96 \pm 3.48$ \\
\hline & LEGE 08333_D & $106.90 \pm 5.38$ & $85.02 \pm 1.57$ & $80.56 \pm 5.12$ \\
\hline & LEGE 15488_D & $99.09 \pm 4.96$ & $36.76 \pm 23.26$ & $20.17 \pm 15.65$ \\
\hline & LEGE 181148_E & $93.04 \pm 6.94$ & $64.14 \pm 14.46$ & $48.58 \pm 4.75$ \\
\hline & LEGE 181148_F & $93.49 \pm 6.54$ & $71.52 \pm 20.38$ & $48.44 \pm 2.02$ \\
\hline & LEGE 181149_D & $94.01 \pm 7.29$ & $64.47 \pm 22.29$ & $40.25 \pm 2.66$ \\
\hline Selection threshold & LEGE 05292_C $+3 \sigma$ & 82.12 & 17.03 & \\
\hline Staurosporine & & $31.67 \pm 6.84$ & $20.07 \pm 4.40$ & $12.05 \pm 2.55$ \\
\hline
\end{tabular}

\subsection{Group A: Metabolomics Analysis and Dereplication of the Putative Active Molecules}

In an attempt to discover which metabolites could be responsible for the observed activity, an untargeted metabolomics analysis was performed. The metabolomes of fractions of group A were compared with a group of 12 fractions without activity on cancer spheroids (group C; Table 1). The extracted mass features with MZmine 2 were submitted to fold change (FC) analysis in MetaboAnalyst 5.0, which allowed for the potential differences 
in the metabolite profiles to be identified, and hence the bioactive compounds could be highlighted.

The chemical space of A/C was then represented as a molecular network constructed using the feature-based molecular networking workflow [21]. The characterization of the molecular families and annotation of compounds were estimated based on the integration of the in silico tools available from the Global Natural Product Social Molecular Networking (GNPS) platform: DEREPLICATOR [22], MS2LDA [23], Network Annotation Propagation (NAP) [24], and MolNetEnhancer [25]. The size of the nodes in the molecular networks was represented relative to the $\log 2(\mathrm{FC})$ (Figure $4 \mathrm{~A}$ ).

A

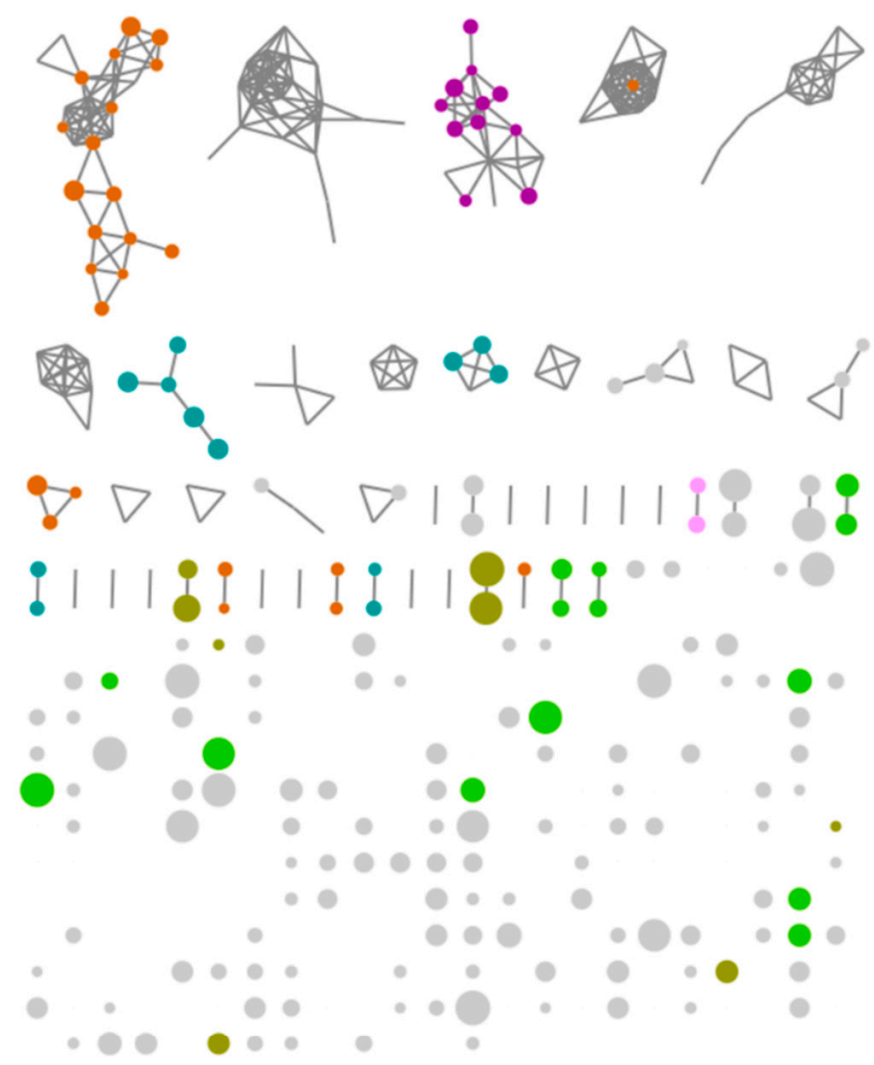

\section{B}

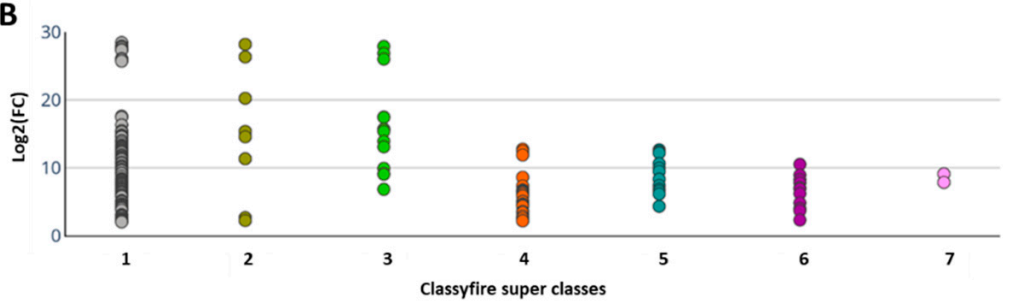

Legend:

No matches (1) O Organic Polymers (2) O Organic acids and derivatives (3) $\bigcirc$ Lipids and lipid-like molecules (4)
Organoheterocyclic compounds (5) $\bigcirc$ Organic oxygen compounds (6) $\bigcirc$ Phenylpropanoids and polyketides (7)

Figure 4. Feature-based molecular network of groups A/C annotated with MolNetEnhancer workflow. The nodes are color-coded accordingly to the ClassyFire super class classification, and their size is related to their fold change $\log 2(\mathrm{FC})$ value (A). Distribution of the nodes with $\log 2(\mathrm{FC})$ higher than 2 through each ClassyFire super class (B).

The analysis of the molecular network revealed 191 nodes with $\log 2(\mathrm{FC})$ between 2.00 and 28.45 , of which 72 nodes were characterized as $13 \%$ lipids and lipid-like molecules, $8 \%$ organic acids and derivatives, $6 \%$ organic oxygen compounds, $6 \%$ organoheterocyclic compounds, $4 \%$ organic polymers, and $1 \%$ phenylpropanoids and polyketides, according 
to the ClassyFire super class classification [26]. The 17 top features with highest fold change $(\geq 20)$ were distributed between the super classes' organic polymers, organic acids and derivatives, and the category of no matches (Figure 4B). Such high fold change values reflect the uniqueness of these mass features among the studied metabolomes, which were found for all the active fractions except for LEGE 15488_C (Table 2). Detailed examination of these 17 ions indicated the majority to be related to the cytotoxic compounds portoamides A, B, and C, known to be produced by Phormidium sp. LEGE 05292 (Table 2) [27].

Table 2. Characterization and annotation of the putative cytotoxic molecules present in the active fractions of group A.

\begin{tabular}{|c|c|c|c|c|c|c|c|}
\hline$m / z$ & $\begin{array}{l}\text { Isotope/ } \\
\text { Fragments }\end{array}$ & Rt (min) & $\log 2(\mathrm{FC})$ & $\begin{array}{l}\text { Super } \\
\text { Class }\end{array}$ & $\begin{array}{l}\text { Direct } \\
\text { Parent }\end{array}$ & $\begin{array}{l}\text { Molecular } \\
\text { Framework }\end{array}$ & Putative Annotation \\
\hline \multicolumn{8}{|c|}{ LEGE 05292_C } \\
\hline $\begin{array}{c}1313.6991 \\
{[\mathrm{M}+\mathrm{H}]^{+}}\end{array}$ & & 7.21 & 25.71 & 3 & 8 & 9 & $\begin{array}{c}\text { Portoamide C } \\
\mathrm{C}_{62} \mathrm{H}_{96} \mathrm{~N}_{12} \mathrm{O}_{19} \\
\Delta 0.27 \mathrm{ppm}\end{array}$ \\
\hline $\begin{array}{c}1532.7887 \\
{[\mathrm{M}+\mathrm{H}]^{+}}\end{array}$ & & 7.51 & 28.18 & 2 & 10 & 9 & $\begin{array}{c}\text { Portoamide A } \\
\mathrm{C}_{74} \mathrm{H}_{109} \mathrm{~N}_{13} \mathrm{O}_{22} \\
\Delta 0.27 \mathrm{ppm}\end{array}$ \\
\hline $\begin{array}{c}1502.7780 \\
{[\mathrm{M}+\mathrm{H}]^{+}}\end{array}$ & & 7.74 & 26.34 & 2 & 10 & 9 & $\begin{array}{c}\text { Portoamide B } \\
\mathrm{C}_{73} \mathrm{H}_{107} \mathrm{~N}_{13} \mathrm{O}_{21} \\
\Delta 0.18 \mathrm{ppm}\end{array}$ \\
\hline \multicolumn{8}{|c|}{ LEGE 17548_C } \\
\hline $\begin{array}{l}1154.6172 \\
{[\mathrm{M}+\mathrm{Na}]^{+}}\end{array}$ & & 8.73 & 26.07 & - & - & - & $\begin{array}{c}\text { [Minutissamide } \mathrm{A}+\mathrm{CH}_{3} \text { ] } \\
\mathrm{C}_{52} \mathrm{H}_{85} \mathrm{~N}_{13} \mathrm{O}_{15} \\
\Delta-1.55 \mathrm{ppm}\end{array}$ \\
\hline $\begin{array}{c}1118.6187 \\
{[\mathrm{M}+\mathrm{H}]^{+}}\end{array}$ & & 8.76 & 26.86 & 3 & 8 & 11 & $\begin{array}{c}\text { Minutissamide A } \\
\mathrm{C}_{51} \mathrm{H}_{83} \mathrm{~N}_{13} \mathrm{O}_{15} \\
\Delta-1.55 \mathrm{ppm}\end{array}$ \\
\hline \multicolumn{8}{|c|}{ LEGE 17548_C, LEGE 17548_D and LEGE 16572_C } \\
\hline $\begin{array}{l}762.5468 \\
{[\mathrm{M}+\mathrm{H}]^{+}}\end{array}$ & & 12.60 & 27.91 & - & - & - & - \\
\hline \multicolumn{8}{|c|}{ LEGE 16572_C } \\
\hline $\begin{array}{l}703.5092 \\
{[\mathrm{M}+\mathrm{H}]^{+}}\end{array}$ & & 12.31 & 27.33 & - & - & - & - \\
\hline \multicolumn{8}{|c|}{ LEGE 181150_D } \\
\hline 895.0778 & $\begin{array}{c}897.0759 \\
{[\mathrm{M}+2 \text { isotope] }}\end{array}$ & 7.92 & 25.98 & - & - & - & Leptochelin \\
\hline 851.1284 & $\begin{array}{c}853.1257 \\
{[\mathrm{M}+2 \text { isotope] }}\end{array}$ & 7.81 & 17.43 & - & - & - & Leptochelin-like* \\
\hline 1011.8493 & & 14.57 & 27.92 & - & - & - & - \\
\hline \multicolumn{8}{|c|}{ LEGE 15488_C } \\
\hline $655.3808[\mathrm{M}+\mathrm{H}]^{+}$ & & 5.73 & 8.27 & - & - & - & - \\
\hline $858.5795[\mathrm{M}+\mathrm{H}]^{+}$ & & 7.29 & 8.10 & - & - & - & - \\
\hline & 331.2010 & 7.28 & 8.15 & - & - & - & - \\
\hline & 528.3863 & 7.28 & 9.05 & 3 & 12 & 11 & - \\
\hline $\begin{array}{c}1520.7861 \\
{[\mathrm{M}+\mathrm{H}]^{+}}\end{array}$ & & 7.87 & 5.07 & 2 & 10 & 9 & $\begin{array}{c}\text { Portoamide-like * } \\
\mathrm{C}_{73} \mathrm{H}_{109} \mathrm{~N}_{13} \mathrm{O}_{22} \\
\Delta-1.44 \mathrm{ppm}\end{array}$ \\
\hline
\end{tabular}

2-Organic polymers; 3-organic acids and derivatives; 8-cyclic peptides; 9-aromatic heteropolycyclic compounds; 10-polypeptides 11-aliphatic heteropolycyclic compounds; 12 -Cyclic depsipeptides; * tentative identification. 
Moreover, in the fraction C of the unidentified Nostocales LEGE 17548 the cyclic lipopeptide minutissamide A was putatively annotated, together with an ion at $m / z$ 1154.6172 $[\mathrm{M}+\mathrm{Na}]^{+}$, that could correspond to a methylated minutissamide A $(+14.01 \mathrm{Da}$ mass shift). Minutissamide A was previously isolated from cultures of Anabaena minutissima (UTEX 1613), and its antiproliferative activity characterized using HT-29 human colon cancer cells $\left(\mathrm{IC}_{50}\right.$ of $\left.2.0 \mu \mathrm{M}\right)$ [28], which correlates well with our bioactivity findings. However, Anabaena minutissima (UTEX 1613) and the unidentified Nostocales LEGE 17548 fall in different clades according to our phylogenetic study, the latter being more related to strains of the genus Halotia (Figure 1).

It is interesting to note that in the case of portoamides or minutissamides, the molecular network was not able to form clusters containing related ions. The absence of clustering led to poor propagation of library annotation as was observed for the sodium or potassium adducts of portoamides and minutissamides that were classified as "no matches".

Furthermore, four mass features, with significant fold change, could not be classified or dereplicated using the GNPS in silico tools or manual search in the databases Dictionary of Natural Products and CyanoMetDB [29], making them potential targets for the isolation of novel active compounds. Of these, the mass feature 897.0759 found in fraction LEGE 181150_D (Table 2) formed a cluster with another ion at $m / z 853.1257$ $(7.81 \mathrm{~min} ; \log 2(\mathrm{FC})=17.43)$; analysis of the mass spectrum showed that these masses were in fact $\mathrm{M}+2$ isotope peaks, thus revealing the presence of halogenated atoms in these molecules. The complexity of the isotopic pattern suggests a combination of chlorine and/or bromine atoms (Figure 5). In addition, the mass difference of 43.94 Da between the compounds might correspond to $\mathrm{Cl} \leftrightarrow \mathrm{Br}$ change. Preliminary GNPS experiments led us to two $\mathrm{PhD}$ theses reporting leptochelin (formerly phormidamide) [30,31], a compound with $m / z 895.0786$ and whose mass spectrum and isotopic pattern are very similar to our findings $(m / z$ 895.0778; $\Delta 0.8 \mathrm{mDa})$. Nevertheless, the structure of this compound seems to not be fully elucidated yet. According to both reports, the compound presented potent cytotoxicity towards mouse neuro-2a neuroblastoma cells $\left(\mathrm{LD}_{50}=1.2 \mu \mathrm{M}\right)$ [30] and human NCI-H460 lung cancer cells ( $\mathrm{IC}_{50}=153 \mathrm{nM}$ ) [31], which is in line with the strong reduction of cell viability observed in our assays (Table 1). Leptochelin was isolated from the Red Sea Leptolyngbya sp. RS02 and from the Indonesian Leptolyngbya sp. HB_3/1/2, which share identical 16S rRNA gene sequences even though they were collected in different geographical locations. Interestingly, our strain, unidentified Synechococcales LEGE 181150, was collected from a marine environment in the Cape Verde archipelago and falls in a subclade apart from the Leptolyngbya strains (Figure 1), suggesting the compound to be produced by a different genus of cyanobacteria. Nevertheless, all these locations fall in the tropical region, which might suggest an ecological role subjacent to the production of this compound.

For fraction C of Phormidium sp. LEGE 15488, there were no mass features with striking values of fold change. This fact could be explained by the similarity in composition to fraction LEGE 15488_D that was included in group C (Figure S3). Thus, for the fraction LEGE 15488_C, the ions with the highest fold change will most probably be the ones responsible for the cytotoxic activity. As such, three protonated molecules were cherrypicked (Table 2). For these molecules, we could not retrieve any dereplication results either using the GNPS tools or manual search in the databases (Dictionary of Natural Products and CyanoMetDB). For the protonated molecule at $m / z$ 1520.7861, the ClassyFire categories Direct Parent (descriptor for the largest structural feature that defines a compound) and Molecular Framework (descriptor for overall aliphaticity / aromaticity and number of cycles) suggested this compound to have a scaffold of the cyclic peptide-type containing aromatic amino acids. In addition to this in silico prediction, the presence of the doubly charged ion at $m / z 760.8961[\mathrm{M}+2 \mathrm{H}]^{2+}$ also reinforces the possible large structure of this compound. Considering these observations and given the taxonomic position of Phormidium sp. LEGE 15488 and Phormidium sp. LEGE 05292 (Figure 1), we hypothesize that this mass could correspond to an undescribed portoamide-type compound with a proposed molecular 
formula of $\mathrm{C}_{73} \mathrm{H}_{109} \mathrm{~N}_{13} \mathrm{O}_{22}$ (calculated for 1519.7810). As for the parent mass 858.5795 $[\mathrm{M}+\mathrm{H}]^{+}$, it was found to be associated with the ESI in-source fragments at $m / z 331.2010$ and 528.3863. For the latter, the in silico annotation can give insights into the nature of this molecule, as it was categorized as a possible cyclic depsipeptide without aromatic amino acids (Table 2).

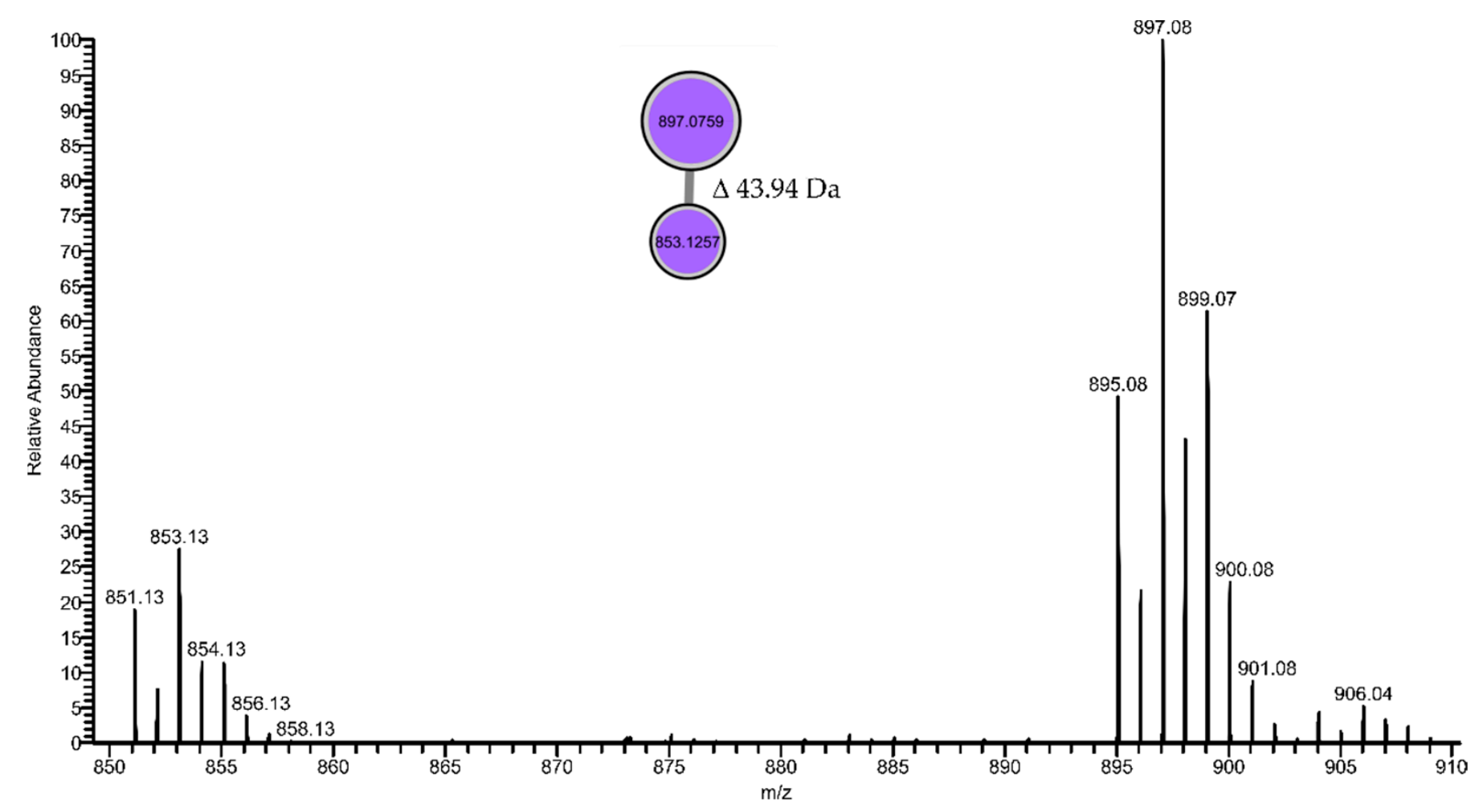

Figure 5. Mass spectrum and the respective cluster of two halogenated compounds present in fraction D of the unidentified Synechococcales LEGE 181150. The nodes are color-coded accordingly to the identity of the fraction. These mass features were exclusively found in the unidentified Synechococcales LEGE 181150.

In this group of cytotoxic fractions, it is worth noting the following aspects: the group is mainly constituted by polar fractions (fraction C); the in silico chemical classification predicted the significant mass features to have a peptide-type scaffold (Figure 4B, Table 2); and the in silico dereplication lead to the putative annotation/identification of known peptides whose cytotoxic activity towards cancer cells had been previously described. Given that these predictions worked correctly with Phormidium sp. LEGE 05292 (strain producer of portoamides), we hypothesize that the strains Phormidium sp. LEGE 15488 (Amazon River, Brazil; Table S1) and the unidentified Nostocales LEGE 17548 (Mira lagoon, Beira Litoral, Portugal; Table S1) might be potential producers of cytotoxic peptide-type compounds. Furthermore, the strains Gloeothece sp. LEGE 16572 (isolated from a fountain, Monchique, Portugal; Table S1) and unidentified Synechococcales LEGE 181150 have potential for the discovery of totally unknown structures.

\subsection{Group B: Metabolomics Analysis and Dereplication of the Putative Active Molecules}

The same untargeted metabolomics approach described above was applied for group $B$. The fold change analysis highlighted 34 mass features with $\log 2(\mathrm{FC})$ between 2.14 and 17.13. Fifteen nodes were characterized, according to ClassyFire superclass, as organoheterocyclic compounds all belonging to the tetrapyrroles and derivatives class $(23 \%)$ and phenylpropanoids and polyketides (21\%) (Figure 6). Contrary to group A, in group B there were no mass features with high fold change values. In fact, the only three mass features that presented $\log 2(\mathrm{FC})$ higher than 10 were $636.4814,1245.5650$, and 1267.5473. The $m / z 636.4814(12.9 \mathrm{~min} ; \log 2(\mathrm{FC})=17.14)$ was found in samples LEGE 16502_E and 
LEGE 15546_D, being characterized as a potential macrolide-type compound. However, its manual query on the mass databases did not retrieve any identification.
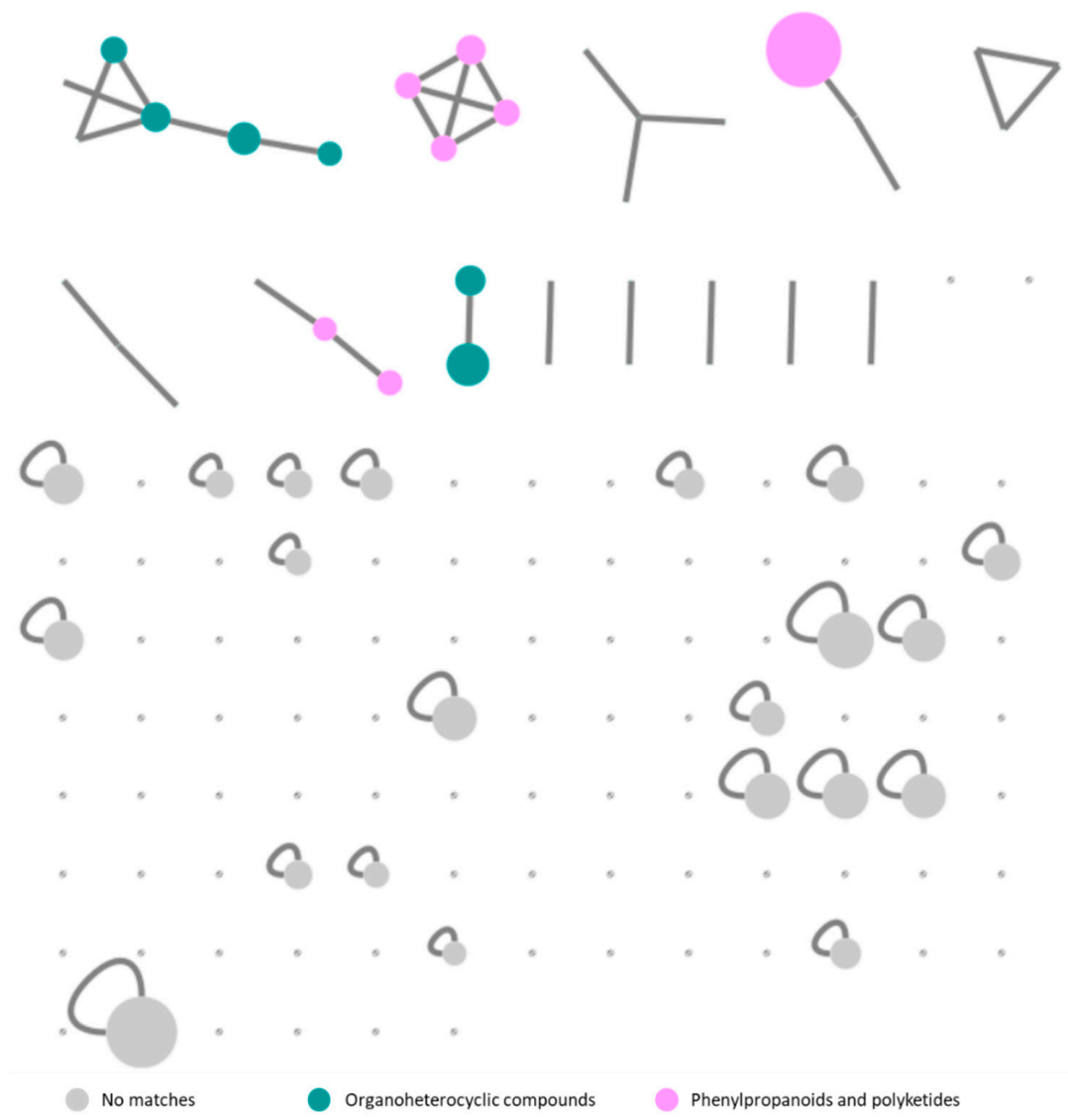

Figure 6. Feature-based molecular network of groups B/C annotated with MolNetEnhancer workflow. The nodes are color-coded accordingly to the ClassyFire super class classification, and their size is related to their fold change $\log 2(\mathrm{FC})$ value.

The mass features 1245.5650 and 1267.5473 , respectively, with $\log 2(\mathrm{FC})$ of 15.85 and 11.59 , were found to be the $[2 \mathrm{M}+\mathrm{H}]^{+}$and $[2 \mathrm{M}+\mathrm{Na}]^{+}$ions of the protonated molecule at $\mathrm{m} / \mathrm{z}$ $623.2865(11.68 \mathrm{~min} ; \log 2(\mathrm{FC})=7.54)$, predicted as a tetrapyrrole-type molecule. Despite this classification, the putative annotation via GNPS tools was not successful. Thus, $13^{2}$ hydroxy-phaeophorbide a methyl ester, was tentatively identified by manual search in the Dictionary of Natural Products and study of its MS2 fragmentation pattern (Table 3, Figure S4). This compound was found to be one of the main components of the samples LEGE 16572_D, LEGE 15546_D, and LEGE xx358_D (Figure 6, Table 3). This putative pheophorbide appeared clustered with a protonated molecule at $\mathrm{m} / z 609.2706$ (11.30 min; $\log 2(\mathrm{FC})=3.90)$. The difference of $14.01 \mathrm{Da}$ between the molecules suggested the loss of a methyl group, and thus was tentatively identified as $13^{2}$-hydroxy-pheophorbide a. This molecule was found in the environmental sample of a cyanobacterial mat (JM1_amb_E) and in the strain Brasilonema sp. LEGE 16502 (LEGE 16502_E). Moreover, further manual dereplication led to the tentative identification of other pheophytins and pheophorbides (Table 3). The lack of GNPS annotation for these compounds might be due to the fact that the masses deposited in the GNPS database were acquired in low resolution mass spectrometers, and thus, did not match with our search criteria. 
Table 3. Characterization and annotation of the putative cytotoxic molecules present in the active fractions of group B.

\begin{tabular}{|c|c|c|c|c|c|}
\hline$m / z$ & Rt (min) & $\log 2(\mathrm{FC})$ & Super Class & Precursor Intensity & Tentative Identification \\
\hline \multicolumn{6}{|c|}{ LEGE 16572_D, LEGE 15546_D and LEGE xx358_D } \\
\hline $\begin{array}{l}653.2971 \\
{[\mathrm{M}+\mathrm{H}]^{+}}\end{array}$ & 12.12 & 7.72 & 1 & $1.19 \times 10^{10}$ & $\begin{array}{c}\text { 15'-hydroxy-lactone-pheophorbide a ethyl ester } \\
\mathrm{C}_{37} \mathrm{H}_{40} \mathrm{~N}_{4} \mathrm{O}_{7} \\
\Delta 0.19 \mathrm{ppm}\end{array}$ \\
\hline $\begin{array}{l}623.2865 \\
{[\mathrm{M}+\mathrm{H}]^{+}}\end{array}$ & 11.68 & 7.54 & 1 & $2.55 \times 10^{10}$ & $\begin{array}{c}\text { 132-hydroxy-phaeophorbide a methyl ester } \\
\mathrm{C}_{36} \mathrm{H}_{38} \mathrm{~N}_{4} \mathrm{O}_{6} \\
\Delta 0.14 \mathrm{ppm}\end{array}$ \\
\hline $\begin{array}{l}639.2813 \\
{[\mathrm{M}+\mathrm{H}]^{+}}\end{array}$ & 11.88 & 5.99 & 2 & $2.44 \times 10^{9}$ & $\begin{array}{l}\text { 15'-hydroxy-lactone-pheophorbide a methyl ester } \\
\qquad \mathrm{C}_{36} \mathrm{H}_{38} \mathrm{~N}_{4} \mathrm{O}_{7} \Delta-0.04 \mathrm{ppm}\end{array}$ \\
\hline \multicolumn{6}{|c|}{ LEGE 16502_E, JM1_amb_E } \\
\hline $\begin{array}{l}593.2759 \\
{[\mathrm{M}+\mathrm{H}]^{+}}\end{array}$ & 11.77 & 6.99 & 2 & $2.97 \times 10^{10}$ & $\begin{array}{c}\text { pheophorbide a } \\
\mathrm{C}_{35} \mathrm{H}_{36} \mathrm{~N}_{4} \mathrm{O}_{5} \\
\Delta 0.09 \mathrm{ppm}\end{array}$ \\
\hline $\begin{array}{l}535.2704 \\
{[\mathrm{M}+\mathrm{H}]^{+}}\end{array}$ & 12.24 & 4.18 & 2 & $3.85 \times 10^{9}$ & $\begin{array}{l}\text { pyrophaeophorbide a } \\
\mathrm{C}_{33} \mathrm{H}_{34} \mathrm{~N}_{4} \mathrm{O}_{3} \Delta 0.06 \mathrm{ppm}\end{array}$ \\
\hline $\begin{array}{l}609.2706 \\
{[\mathrm{M}+\mathrm{H}]^{+}}\end{array}$ & 11.29 & 3.90 & 1 & $5.22 \times 10^{8}$ & $\begin{array}{c}\text { 132-hydroxy-phaeophorbide a } \\
\mathrm{C}_{35} \mathrm{H}_{36} \mathrm{~N}_{4} \mathrm{O}_{6} \\
\Delta-0.26 \mathrm{ppm}\end{array}$ \\
\hline \multicolumn{6}{|c|}{ All samples } \\
\hline $\begin{array}{l}903.5618 \\
{[\mathrm{M}+\mathrm{H}]^{+}}\end{array}$ & 14.41 & 4.58 & 2 & $1.47 \times 10^{10}$ & $\begin{array}{l}\text { 15 }{ }^{1} \text {-hydroxy-lactone-phaeophytin a } \\
\mathrm{C}_{55} \mathrm{H}_{74} \mathrm{~N}_{4} \mathrm{O}_{7} \Delta-1.36 \mathrm{ppm}\end{array}$ \\
\hline $\begin{array}{l}887.5664 \\
{[\mathrm{M}+\mathrm{H}]^{+}}\end{array}$ & 14.30 & 3.67 & & $4.80 \times 10^{10}$ & $\begin{array}{l}13^{2} \text {-hydroxy-pheophytin a } \\
\mathrm{C}_{55} \mathrm{H}_{74} \mathrm{~N}_{4} \mathrm{O}_{6} \Delta-1.93 \mathrm{ppm}\end{array}$ \\
\hline \multicolumn{6}{|c|}{ JM1_amb_D, JM1_amb_E, LEGE 16502_E } \\
\hline $\begin{array}{l}917.5777 \\
{[\mathrm{M}+\mathrm{H}]^{+}}\end{array}$ & 14.70 & 2.16 & 2 & $2.02 \times 10^{9}$ & $\begin{array}{l}\text { 13-methyldioxy-phaeophytin a/ } \\
\text { ficusmicrochlorin B } \\
\text { C56H76N4O7 } \\
\Delta-1.07 \mathrm{ppm}\end{array}$ \\
\hline
\end{tabular}

1-No Matches, 2-Organic polymers.

These pheophytins and pheophorbides are products of the degradation pathway of chlorophyll a, and their anticancer activity has been widely reported [32] Such molecules are commonly found in photosynthetic organisms, which suggests that the bioactivity results obtained for group $B$ could be related to a higher content of these compounds in the fractions. Future studies will help to elucidate this observation and address possible ecological relationships.

\section{Materials and Methods}

\subsection{Cyanobacteria Culture Conditions}

The 60 cyanobacterial strains were obtained from the Blue Biotechnology and Ecotoxicology Culture Collection (LEGE-CC) (Table S1). To establish the natural products library, these microorganisms were cultured up to $4 \mathrm{~L}$, in the appropriate growth media, and maintained under standard laboratory conditions: $25^{\circ} \mathrm{C}$ with light/dark cycle of $14 / 10 \mathrm{~h}$ at a light intensity of 10-30 $\mu \mathrm{mol}$ photons $\mathrm{m}^{-2} \mathrm{~s}^{-1}$. The freshwater strains were cultured using Z8 medium, while the marine strains were grown using Z8 medium supplemented with $25 \%$ of synthetic sea salts (Tropic marin, Berlin, Germany) and $1 \%$ of vitamin $B_{12}$ (Table S1). Depending on the strain, after 30 to 160 days of growth, the biomass was harvested either by centrifugation for unicellular strains, or by filtration for filamentous strains, through an appropriately sized mesh. All biomasses were freeze-dried (LyoQuest, Telstar, Terrassa, Spain) before organic extraction. 


\subsection{DNA Extraction, Amplification (PCR) and Sequencing}

Twelve strains of cyanobacteria were characterized for the first time in this work (Figure 1). For taxonomic studies, these strains were grown in $50 \mathrm{~mL}$ culture flasks and cells were harvested after 15-20 days of cultivation. Genomic DNA was extracted using the Genomic DNA Mini Kit (Invitrogen, Waltham, MA, USA), according to the manufacturer's instructions for Gram-negative bacteria. To obtain the complete sequence of 16S rRNA gene, PCR amplification was performed using the oligonucleotide primers set 27F [33] and 23S30R [34]. PCR reactions were performed in a final volume of $20 \mu \mathrm{L}$ containing $1 \times$ Green GoTaq Flexi Buffer, $2.5 \mathrm{mM}$ of $\mathrm{MgCl}_{2}, 125.0 \mathrm{mM}$ of each deoxynucleotide triphosphate, $1.0 \mu \mathrm{M}$ of each primer, 0.5 U of GoTaq Flexi DNA Polymerase (Promega, Madison, WI, USA), $10 \mathrm{mg} \mathrm{mL}^{-1}$ of bovine serum albumin (BSA), and 10-30 $\mathrm{ng}$ of template DNA, on a TProfessional Standard thermal cycler (Biometra, Göttingen, Germany). The PCR conditions were as follows: initial denaturation at $94^{\circ} \mathrm{C}$ for $5 \mathrm{~min}$, followed by 10 cycles of denaturation at $94{ }^{\circ} \mathrm{C}$ for $45 \mathrm{~s}$, annealing at $57^{\circ} \mathrm{C}$ for $45 \mathrm{~s}$, and extension at $72{ }^{\circ} \mathrm{C}$ for $2 \mathrm{~min}$, followed by 25 cycles of denaturation at $92{ }^{\circ} \mathrm{C}$ for $45 \mathrm{~s}$, annealing at $54{ }^{\circ} \mathrm{C}$ for $45 \mathrm{~s}$, and extension at $72{ }^{\circ} \mathrm{C}$ for $2 \mathrm{~min}$ with a final elongation step at $72{ }^{\circ} \mathrm{C}$ for $7 \mathrm{~min}$. The PCR reactions were performed in duplicate. PCR products were separated by $1.5 \%$ agarose gel stained with SYBR ${ }^{\circledR}$ safe (Invitrogen, Waltham, MA, USA) and DNA fragments with the expected size were excised and purified using NZYGelpure (NzyTech, Genes and Enzymes, Lisbon, Portugal) according to the manufacturer's instructions. Since the sequences were obtained by direct sequencing of purified amplicons, internal primers CYA359F, CYA781R [35], and 1494R [33] were used to improve the quality of the sequences. The sequencing was performed at GATC Biotech (Ebersberg, Germany) and the nucleotide sequences obtained were manually inspected for quality and assembled using the Geneious 11.1.5 software (Biomatters Ltd., Auckland, New Zealand). Possible chimera formation during the sequences was checked using the software DECIPHER [36] before any phylogenetic analysis. Sequences obtained were inserted in the BLASTn (Basic Local Alignment and Search Tool for Nucleotides) database and the results were analyzed. The sequences associated with this study were deposited in the GenBank database under the accession numbers MW790910 to MW790921 (Table S1).

\subsection{Phylogenetic Analysis}

A total of 146 sequences were used in the final analysis, including 2 strains of Gloeobacter violaceus as outgroup, 85 sequences of cyanobacteria including type and reference strains retrieved from GenBank (National Center for Biotechnology Information, NCBI, Bethesda, MD, USA), and 59 sequences of LEGE-CC strains from which 12 were obtained in this work. Multiple sequence alignment was constructed using ClustalW in MEGA7 [37,38], and sequences were manually proofread and edited. Maximum likelihood (ML) analysis was carried out using substitution model GTR+G+I according to the Bayesian information criterion (BIC) and Akaike information criterion (AIC) scores with 1000 bootstrap resampling replicates using the MEGA7 software [38]. The final phylogenetic tree was edited on iTOL (Interactive Tree of Life) [39].

\subsection{Cyanobacterial Natural Products Library}

The LEGE-NPL (natural products library) solid inventory is composed of crude extracts. Thus, freeze-dried biomass was extracted three times with $\mathrm{MeOH}$, with a sonication step of $5 \mathrm{~min}$ in between extractions, and was filtered and concentrated at $30^{\circ} \mathrm{C}$, using a rotary evaporator. The yields of extraction are described in the Supplementary Material (Figure S1). The extracts were then fractionated by reverse-phase HPLC in a Waters Alliance e2695 Separations Module instrument, coupled to a photodiode array detector (Waters 2998 PDA) and an automatic Waters Fraction Collector III (Waters, Mildford, MA, USA). Each crude was injected at $40 \mathrm{mg} \mathrm{mL}^{-1}(500 \mu \mathrm{L} ; 1 \mathrm{~mL}$ loop) and separated on an ACE 10 $\mathrm{C} 8$ column $\left(50 \times 10 \mathrm{~mm}, \mathrm{ACE}\right.$, Reading, UK), using a $\mathrm{H}_{2} \mathrm{O}: \mathrm{MeCN}$ gradient (Table 4). Hence, each cyanobacterial extract was chromatographed into eight fractions $(4 \mathrm{~mL}$ final volume, 
named A-H) into 48-deep well plates (Riplate, Ritter, Schwabmünchen, Germany), which were then dried on a CentriVap Concentrator (LabConco, Kansas City, MO, USA). These fractions were solubilized in $500 \mu \mathrm{L}$ of DMSO and transferred to 96-deep well microplates (Nest Scientific, Woodbridge Township, NJ, USA) and stored at $-80^{\circ} \mathrm{C}$, thus forming the LEGE-NPL liquid library (mother plates).

Table 4. HPLC chromatographic and collection program for generating the fractions for LEGE-NPL liquid inventory.

\begin{tabular}{cccccc}
\hline Time (min) & $\begin{array}{c}\text { Flow } \\
\left(\mathbf{m L} \cdot \mathbf{m i n}^{-\mathbf{1})}\right.\end{array}$ & $\mathbf{M e C N}(\mathbf{\%})$ & $\mathbf{H}_{\mathbf{2}} \mathbf{O}(\mathbf{\%})$ & $\begin{array}{c}\text { Collection Time } \\
(\mathbf{m i n})\end{array}$ & Fraction \\
\hline 0.0 & 3.0 & 10 & 90 & $1.00-2.30$ & $\mathrm{~A}$ \\
2.0 & 3.0 & 80 & 20 & $2.30-3.60$ & $\mathrm{~B}$ \\
3.0 & 3.0 & 80 & 20 & $3.60-4.90$ & $\mathrm{C}$ \\
4.0 & 3.0 & 100 & 0 & $4.90-6.20$ & $\mathrm{D}$ \\
8.9 & 3.0 & 100 & 0 & $6.20-7.50$ & $\mathrm{E}$ \\
9.2 & 3.5 & 100 & 0 & $7.50-8.80$ & $\mathrm{~F}$ \\
12.0 & 3.5 & 100 & 0 & $8.80-10.36$ & $\mathrm{G}$ \\
12.3 & 3.0 & 100 & 0 & $10.36-11.50$ & $\mathrm{H}$ \\
14.0 & 3.0 & 100 & 0 & & \\
15.0 & 3.0 & 10 & 90 & & \\
18.0 & 3.0 & 10 & 90 & & \\
\hline
\end{tabular}

\subsection{Cell Culture}

The human colon carcinoma cell line HCT 116 was obtained from Sigma-Aldrich (St. Louis, MO, USA) and the human brain endothelial cell line hCMEC/D3 was kindly donated by Dr. P. O. Courad (INSERM, Paris, France). HCT 116 was cultured with McCoy's 5A medium (CarlRoth, Kasruw, Germany) and hCMEC/D3 with Dulbecco's modified Eagle medium (DMEM) (Gibco, Thermo Fisher Scientific, Waltham, MA, USA), both supplemented with 10\% of fetal bovine serum (Biochrom, Berlin, Germany), 1\% of penicillin/streptomycin (Biochrom, Berlin, Germany), and 0.1\% of amphotericin (GE Healthcare, Little Chafont, Buckinghamshire, UK). Both cell lines were grown at $37^{\circ} \mathrm{C}$ with $5 \% \mathrm{CO}_{2}$ atmosphere.

\subsection{Bioactivity Screening Using 2D Cell Models}

The HCT 116 and hCMEC/D3 cells were seeded on 96-well plates, at a density of $3.3 \times 10^{4}$ cells $\mathrm{mL}^{-1}$ for $24 \mathrm{~h}$. Then, the cells were incubated with $25 \mu \mathrm{g} \mathrm{mL}{ }^{-1}$ of LEGE-NPL fractions ( $0.5 \%$ DMSO final concentration) and $1.25 \mu \mathrm{M}$ of staurosporine (positive control) for $48 \mathrm{~h}$. After this period of exposure, cell viability was evaluated by the MTT colorimetric assay (3-(4,5-dimethylthiazol-2-yl)-2,5-diphenyltetrazolium bromide). Thus, the cells were incubated with $20 \mu \mathrm{L}$ of MTT reagent, at a final concentration of $200 \mu \mathrm{g} \mathrm{mL}^{-1}$ over 3-4 h, and afterwards $100 \mu \mathrm{L}$ of DMSO was used to dissolve formazan crystals. Absorbance was read at $550 \mathrm{~nm}$ on a multi-detection microplate reader (Synergy HT, Biotek, Bart Frederick Shahr, Germany). All assays were repeated three times. Cell viability was calculated using the following formula:

$$
\% \text { cell viability }(\text { to negative control })=\frac{\bar{x}\left(\text { Absorbance }_{\text {sample }}\right)}{\bar{x}\left(\text { Absorbance }_{\text {negative control }}\right)} \times 100
$$

\subsection{Bioactivity Screening Using 3D Cell Models}

The cancer spheroids were produced using the scaffold-free liquid-overlay technique [40]. Briefly, $200 \mu \mathrm{L}$ of McCoy's medium with a HCT 116 cell density of $5 \times 10^{4}$ cells $\mathrm{mL}^{-1}$ was added to ultra-low attachment round-bottom 96-well plates (Costar, Corning, New York, NY, USA). Cells were allowed to settle for $30 \mathrm{~min}$, at room temperature, and then incubated for 5 days, at $37^{\circ} \mathrm{C}$ under $5 \% \mathrm{CO}_{2}$ atmosphere, until the spheroids were properly formed. After renewal of the culture medium, the spheroids were incubated with $25 \mu \mathrm{g} \mathrm{mL}^{-1}$ of 
LEGE-NPL fractions (0.5\% DMSO final concentration) and $1.25 \mu \mathrm{M}$ staurosporine (positive control) for $96 \mathrm{~h}$. Cell viability was evaluated using the acid phosphatase assay. Hence, media was removed, the wells were carefully washed with PBS, and the spheroids were incubated for $2 \mathrm{~h}$ in $100 \mu \mathrm{L}$ of p-nitrophenyl phosphate $\left(2 \mathrm{mg} \mathrm{mL}^{-1}\right)$ in sodium acetate buffer $(0.1 \mathrm{M})$. To stop the reaction, $10 \mu \mathrm{L}$ of $\mathrm{NaOH}(1 \mathrm{~N})$ was added to each well and the absorbance was read at $405 \mathrm{~nm}$ on a multi-detection microplate reader (Synergy HT, Biotek, Bart Frederick Shahr, Germany). All assays were performed in triplicate and cell viability was calculated according to the formula above. Graphics were designed using Plotly Chart Studio [41].

\subsection{Untargeted Metabolomics Analysis}

To identify the putative cytotoxic compounds, an untargeted metabolomics approach was performed. Groups A and B were constituted by the active fractions of the study (Table 1, Figure 4). Group C was constituted by 12 fractions that were not considered active: JM5_amb_D, JM5_amb_E, LEGE 06078_D, LEGE 07092_D, LEGE 07167_C, LEGE 07167_D, LEGE 07167_E, LEGE 08333_D, LEGE 15488_D, LEGE 181148_E, LEGE 181148_F, and LEGE 181149_D. The liquid chromatography-high resolution electrospray ionization tandem mass spectrometry (LC-HRESIMS/MS) data were acquired on a system composed of a Dionex UltiMate 3000 HPLC with a MWD-3000RS UV/VIS detector, coupled to a $Q$ Exactive Focus mass spectrometer controlled by Xcalibur 4.1 software (Thermo Fisher Scientific, Waltham, MA, USA). Then, $5 \mu \mathrm{L}\left(1 \mathrm{mg} \mathrm{mL}^{-1}\right.$ in $\left.\mathrm{MeOH}\right)$ was separated on an ACE UltraCore 2.5 SuperC18 column $\left(75 \times 2.1 \mathrm{~mm}, \mathrm{ACE}\right.$, Reading, UK), at $40^{\circ} \mathrm{C}$, using a gradient from 99.5 to $10 \% \mathrm{H}_{2} \mathrm{O} / \mathrm{MeOH} /$ formic acid (95:5:0.1, v/v) to 0.5 to $90 \%$ isopropanol/MeOH/formic acid (95:5:0.1, $/ 2$ ) for $9.5 \mathrm{~min}$, maintaining the last mixture until $15.5 \mathrm{~min}$ before returning to the initial conditions, with a flow rate of $0.35 \mathrm{~mL} \mathrm{~min}^{-1}$ [42]. The UV absorbance was monitored at $254 \mathrm{~nm}$. HRESIMS-MS was obtained in positive mode using a capillary temperature of $262.5^{\circ} \mathrm{C}$, spray voltage of $3.5 \mathrm{kV}$, full MS scan at the resolution of 70,000 FWHM ( $m / z$ range of $150-2000)$, and data dependent $\mathrm{MS}^{2}\left(\mathrm{ddMS}^{2}\right.$, Discovery mode) at the resolution of 17,500 FWHM (isolation window used was 3.0 amu and normalized collision energy was 35). Raw data files were converted to the mzML format with MSConvert, using the parameters recommended for the Global Natural Product Social Molecular Networking (GNPS) [43]. MZmine 2 v.2.53 (http://mzmine.github.io/) was used to generate the quantification file used in the fold change analysis of MetaboAnalyst 5.0 (https: / / www.metaboanalyst.ca/), and to generate the $\mathrm{MS}^{2}$ spectral summary file and quantification file for feature-based molecular networking (parameters used in MZmine 2 for mass feature detection, chromatogram building, and alignment can be found in Table S2). The appropriate files were uploaded to the GNPS web platform, and the featurebased molecular networking (FBMN) was constructed using the default settings. This molecular network was analyzed with the integrated GNPS tools DEREPLICATOR [22], MS2LDA [23], and Network Annotation Propagation (NAP) [24], which were all combined via the MolNetEnhancer [25] workflow. The web links that gave origin to the results are provided in Table S3 and the structure database used for NAP can be found as Supplementary Material. For the fold change analysis with MetaboAnalyst 5.0, the data was uploaded in comma separated values (.csv) format, with 18 unpaired samples (fractions) in columns and mass features in rows (474 mass features for group A/C and 137 mass features for group B/C; PCA and fold change charts are shown in Figure S5). No data filtering or data normalization was performed, and missing values were replaced by 1 . Cytoscape 3.8.2 was used to combine the GNPS and MetaboAnalyst results and visualize the resulting molecular network. Manual dereplication was done by using the Dictionary of Natural Products 30.1 Chemical Search (https: / / dnp.chemnetbase.com) and CyanoMetDB [29].

\section{Conclusions}

Cyanobacteria have acquired an indisputable role in natural products drug discovery. Our in-house culture collection of cyanobacteria (LEGE-CC) harbors a great potential to 
explore for biotechnological applications, but in prior works, this was often very laborious and unsuccessful. Therefore, there was a need to develop a new strategy to access the chemical richness of LEGE-CC in a more expedited way. In summary, the semiautomated HPLC fractionation of 64 crudes generated 512 fractions that were tested for their cytotoxic potential using different cell models. The conjugation of monolayer assays and 3D cancer spheroids lead to the selection of 11 active fractions, whose chemical space was studied using an untargeted metabolomics approach. The putative annotation and identification of several cytotoxic compounds contributed to expanding the knowledge of the biochemical composition of 7 LEGE-CC strains that were characterized herein for the first time. This study was relevant to prioritize the strains with potential to discover compounds of unknown structure, work that will be addressed in the near future.

Supplementary Materials: The following are available online at https:/ / www.mdpi.com/article/10 $.3390 / \mathrm{md19110633/s1}$, Table S1: List of LEGE-CC strains and environmental samples used in this work. Asterisks $\left({ }^{*}\right)$ represent sequences that were obtained for this work. Table S2: Parameters used in MZmine 2 for mass feature detection, chromatogram building and feature alignment for comparison of group A with C and group B with C. Table S3: GNPS jobs used for the construction of the molecular networks. Figure S1: Boxplot representing the max, min, median and mean amounts of lyophilized biomass (A), MeOH extract (B) and final yield (C). Figure S2: IC50 graphs from the optimization of the MTT and acid phosphatase assays on 3D spheroids of the HCT 116 human colon carcinoma cell line. A range of concentrations, from $0.1 \mathrm{nM}$ to $10 \mu \mathrm{M}$, of the anticancer drug staurosporine was used to determine the most sensitive method for evaluating cytotoxicity in cell spheroids. Figure S3: Total ion chromatograms of fractions LEGE 15488_C (upper) and LEGE 15488_D (lower). Figure S4: MS/MS spectrum of the protonated molecule at $\mathrm{m} / \mathrm{z}$ 623.2865. The MS2 fragments and molecular formula were consistent with the tentative identification of $13^{2}$-hydroxy-phaeophorbide a methyl ester. Figure S5: Principal component analysis (PCA) and fold change plots of the untargeted metabolic analysis of group A/C (A) and group B/C (B).

Author Contributions: Conceptualization, M.R.; methodology, L.F., M.P., R.U., and M.R.; investigation, L.F. (creation of library, bioactivity assays, untargeted metabolomics), J.M., R.S. (DNA extraction, amplification (PCR), sequencing, and phylogenetic analysis), and M.R. (untargeted metabolomics); resources, V.V. and M.R.; data curation, M.R.; writing-original draft preparation, L.F. and M.R.; writing-review and editing, all authors. All authors have read and agreed to the published version of the manuscript.

Funding: This research was developed under CYANCAN project PTDC/MED-QUI/30944/2017, co-financed by NORTE 2020, Portugal 2020, and the European Union through the ERDF, and by FCT through national funds and was additionally supported by the FCT and strategic funds UIDB/04423/2020 and UIDP/04423/2020 andby the project ATLANTIDA (ref. NORTE-01-0145FEDER-000040), supported by the Norte Portugal Regional Operational Program (NORTE 2020), under the PORTUGAL 2020 Partnership Agreement and through the European Regional Development Fund (ERDF).

Institutional Review Board Statement: Not applicable.

Informed Consent Statement: Not applicable.

Data Availability Statement: The data presented in this study are available in the Supplementary Materials.

Acknowledgments: We deeply thank Pedro Leão and the Cyanobacterial Natural Products team at CIIMAR for all the help with the mass spectrometry data acquisition.

Conflicts of Interest: The authors declare no conflict of interest.

\section{References}

1. Newman, D.J.; Cragg, G.M. Natural Products as Sources of New Drugs over the Nearly Four Decades from 01/1981 to 09/2019. J. Nat. Prod. 2020, 83, 770-803. [CrossRef]

2. Khalifa, S.A.M.; Shedid, E.S.; Saied, E.M.; Jassbi, A.R.; Jamebozorgi, F.H.; Rateb, M.E.; Du, M.; Abdel-Daim, M.M.; Kai, G.Y.; Al-Hammady, M.A.M.; et al. Cyanobacteria-from the Oceans to the Potential Biotechnological and Biomedical Applications. Mar. Drugs 2021, 19, 320. [CrossRef] 
3. Demay, J.; Bernard, C.; Reinhardt, A.; Marie, B. Natural Products from Cyanobacteria: Focus on Beneficial Activities. Mar. Drugs 2019, 17, 320. [CrossRef] [PubMed]

4. Nandagopal, P.; Steven, A.N.; Chan, L.-W.; Rahmat, Z.; Jamaluddin, H.; Mohd Noh, N.I. Bioactive Metabolites Produced by Cyanobacteria for Growth Adaptation and Their Pharmacological Properties. Biology 2021, 10, 1061. [CrossRef] [PubMed]

5. Tan, L.T.; Phyo, M.Y. Marine Cyanobacteria: A Source of Lead Compounds and Their Clinically-Relevant Molecular Targets. Molecules 2020, 25, 2197. [CrossRef]

6. Dyshlovoy, S.A.; Honecker, F. Marine Compounds and Cancer: Updates 2020. Mar. Drugs 2020, 18, 643. [CrossRef]

7. Ramos, V.; Morais, J.; Castelo-Branco, R.; Pinheiro, Â.; Martins, J.; Regueiras, A.; Pereira, A.L.; Lopes, V.R.; Frazão, B.; Gomes, D.; et al. Cyanobacterial Diversity Held in Microbial Biological Resource Centers as a Biotechnological Asset: The Case Study of the Newly Established LEGE Culture Collection. J. Appl. Phycol. 2018, 30, 1437-1451. [CrossRef] [PubMed]

8. Gutiérrez-del-Río, I.; Brugerolle de Fraissinette, N.; Castelo-Branco, R.; Oliveira, F.; Morais, J.; Redondo-Blanco, S.; Villar, C.J.; Iglesias, M.J.; Soengas, R.; Cepas, V.; et al. Chlorosphaerolactylates A-D: Natural Lactylates of Chlorinated Fatty Acids Isolated from the Cyanobacterium Sphaerospermopsis sp. LEGE 00249. J. Nat. Prod. 2020, 83, 1885-1890. [CrossRef]

9. Freitas, S.; Silva, N.G.; Sousa, M.L.; Ribeiro, T.; Rosa, F.; Leão, P.N.; Vasconcelos, V.; Reis, M.A.; Urbatzka, R. Chlorophyll Derivatives from Marine Cyanobacteria with Lipid-Reducing Activities. Mar. Drugs 2019, 17, 229. [CrossRef]

10. Sousa, M.L.; Preto, M.; Vasconcelos, V.; Linder, S.; Urbatzka, R. Antiproliferative Effects of the Natural Oxadiazine Nocuolin a Are Associated with Impairment of Mitochondrial Oxidative Phosphorylation. Front. Oncol. 2019, 9, 224. [CrossRef]

11. Freitas, S.; Martins, R.; Costa, M.; Leão, P.; Vitorino, R.; Vasconcelos, V.; Urbatzka, R. Hierridin B Isolated from a Marine Cyanobacterium Alters VDAC1, Mitochondrial Activity, and Cell Cycle Genes on HT-29 Colon Adenocarcinoma Cells. Mar. Drugs 2016, 14, 158. [CrossRef] [PubMed]

12. Ribeiro, T.; Lemos, F.; Preto, M.; Azevedo, J.; Sousa, M.L.; Leão, P.N.; Campos, A.; Linder, S.; Vitorino, R.; Vasconcelos, V.; et al. Cytotoxicity of Portoamides in Human Cancer Cells and Analysis of the Molecular Mechanisms of Action. PLoS ONE 2017, 12, e0188817. [CrossRef] [PubMed]

13. Antunes, J.; Pereira, S.; Ribeiro, T.; Plowman, J.E.; Thomas, A.; Clerens, S.; Campos, A.; Vasconcelos, V.; Almeida, J.R. A MultiBioassay Integrated Approach to Assess the Antifouling Potential of the Cyanobacterial Metabolites Portoamides. Mar. Drugs 2019, 17, 111. [CrossRef]

14. Komárek, J. A Polyphasic Approach for the Taxonomy of Cyanobacteria: Principles and Applications. Eur. J. Phycol. 2016, 51, 346-353. [CrossRef]

15. Gerwick, W.H.; Coates, R.C.; Engene, N.; Gerwick, L.; Grindberg, R.v.; Jones, A.C.; Sorrels, C.M. Giant Marine Cyanobacteria Produce Exciting Potential Pharmaceuticals. Microbe 2008, 3, 277-284. [CrossRef]

16. Thornburg, C.C.; Britt, J.R.; Evans, J.R.; Akee, R.K.; Whitt, J.A.; Trinh, S.K.; Harris, M.J.; Thompson, J.R.; Ewing, T.L.; Shipley, S.M.; et al. NCI Program for Natural Product Discovery: A Publicly-Accessible Library of Natural Product Fractions for High-Throughput Screening. ACS Chem. Biol. 2018, 13, 2484-2497. [CrossRef] [PubMed]

17. Belfiore, L.; Aghaei, B.; Law, A.M.K.; Dobrowolski, J.C.; Raftery, L.J.; Tjandra, A.D.; Yee, C.; Piloni, A.; Volkerling, A.; Ferris, C.J.; et al. Generation and Analysis of 3D Cell Culture Models for Drug Discovery. Eur. J. Pharm. Sci. 2021, 163, 105876. [CrossRef]

18. Sousa, M.L.; Ribeiro, T.; Vasconcelos, V.; Linder, S.; Urbatzka, R. Portoamides A and B Are Mitochondrial Toxins and Induce Cytotoxicity on the Proliferative Cell Layer of in Vitro Microtumours. Toxicon 2020, 175, 49-56. [CrossRef] [PubMed]

19. Kijanska, M.; Kelm, J. In Vitro 3D Spheroids and Microtissues: ATP-Based Cell Viability and Toxicity Assays. In Assay Guidance Manual [Internet]; Eli Lilly\& Company and the National Center for Advancing Translational Sciences: Bethesda, MD, USA, 2016; pp. 1-13.

20. Zhang, J.H.; Chung, T.D.Y.; Oldenburg, K.R. A Simple Statistical Parameter for Use in Evaluation and Validation of High Throughput Screening Assays. J. Biomol. Screen. 1999, 4, 67-73. [CrossRef]

21. Nothias, L.F.; Petras, D.; Schmid, R.; Dührkop, K.; Rainer, J.; Sarvepalli, A.; Protsyuk, I.; Ernst, M.; Tsugawa, H.; Fleischauer, M.; et al. Feature-Based Molecular Networking in the GNPS Analysis Environment. Nat. Methods 2020, 17, 905-908. [CrossRef]

22. Mohimani, H.; Gurevich, A.; Shlemov, A.; Mikheenko, A.; Korobeynikov, A.; Cao, L.; Shcherbin, E.; Nothias, L.F.; Dorrestein, P.C.; Pevzner, P.A. Dereplication of Microbial Metabolites through Database Search of Mass Spectra. Nat. Commun. 2018, 9, 4035. [CrossRef] [PubMed]

23. Wandy, J.; Zhu, Y.; van der Hooft, J.J.J.; Daly, R.; Barrett, M.P.; Rogers, S. Ms2lda.Org: Web-Based Topic Modelling for Substructure Discovery in Mass Spectrometry. Bioinformatics 2018, 34, 317-318. [CrossRef]

24. Da Silva, R.R.; Wang, M.; Nothias, L.F.; van der Hooft, J.J.J.; Caraballo-Rodríguez, A.M.; Fox, E.; Balunas, M.J.; Klassen, J.L.; Lopes, N.P.; Dorrestein, P.C. Propagating Annotations of Molecular Networks Using in Silico Fragmentation. PLoS Comput. Biol. 2018, 14, e1006089. [CrossRef] [PubMed]

25. Ernst, M.; Kang, K.B.; Caraballo-Rodríguez, A.M.; Nothias, L.F.; Wandy, J.; Chen, C.; Wang, M.; Rogers, S.; Medema, M.H.; Dorrestein, P.C.; et al. Molnetenhancer: Enhanced Molecular Networks by Integrating Metabolome Mining and Annotation Tools. Metabolites 2019, 9, 144. [CrossRef]

26. Djoumbou Feunang, Y.; Eisner, R.; Knox, C.; Chepelev, L.; Hastings, J.; Owen, G.; Fahy, E.; Steinbeck, C.; Subramanian, S.; Bolton, E.; et al. ClassyFire: Automated Chemical Classification with a Comprehensive, Computable Taxonomy. J. Cheminform. 2016, 8, 61. [CrossRef] [PubMed] 
27. Leao, P.N.; Pereira, A.R.; Liu, W.-T.; Ng, J.; Pevzner, P.a.; Dorrestein, P.C.; Konig, G.M.; Vasconcelos, V.M.; Gerwick, W.H. Synergistic Allelochemicals from a Freshwater Cyanobacterium. Proc. Natl. Acad. Sci. USA 2010, 107, 11183-11188. [CrossRef]

28. Kang, H.S.; Krunic, A.; Shen, Q.; Swanson, S.M.; Orjala, J. Minutissamides A-D, Antiproliferative Cyclic Decapeptides from the Cultured Cyanobacterium Anabaena Minutissima. J. Nat. Prod. 2011, 74, 1597-1605. [CrossRef]

29. Jones, M.R.; Pinto, E.; Torres, M.A.; Dörr, F.; Mazur-Marzec, H.; Szubert, K.; Tartaglione, L.; Dell'Aversano, C.; Miles, C.O.; Beach, D.G.; et al. CyanoMetDB, a Comprehensive Public Database of Secondary Metabolites from Cyanobacteria. Water Res. 2021, 196, 117017. [CrossRef]

30. Vulpanovici, F.A. Biosynthesis, Production and Structural Studies of Secondary Metabolites in Cultured Marine Cyanobacteria. Ph.D. Thesis, Oregon State University, Corvallis, OR, USA, 2004.

31. Thornburg, C.C. Investigation of Unique Marine Environments for Microbial Natural Products. Ph.D. Thesis, Oregon State University, Corvallis, OR, USA, 2013; pp. 1-276.

32. Saide, A.; Lauritano, C.; Ianora, A. Pheophorbide A: State of the Art. Mar. Drugs 2020, 18, 257. [CrossRef]

33. Lane, D.J. 16S/23S rRNA sequencing. In Nucleic Acid Techniques in Bacterial Systematics; John Wiley and Sons: Chichester, UK, 1991; pp. 115-175.

34. Lepère, C.; Wilmotte, A.; Meyer, B. Molecular Diversity of Microcystis Strains (Cyanophyceae, Chroococcales) Based on $16 \mathrm{~S}$ RDNA Sequences. Syst. Geogr. Plants 2000, 70, 275-283. [CrossRef]

35. Nübel, U.; Garcia-Pichel, F.; Muyzer, G. PCR Primers to Amplify 16S RRNA Genes from Cyanobacteria. Appl. Environ. Microbiol. 1997, 63, 3327-3332. [CrossRef]

36. Wright, E.S.; Yilmaz, L.S.; Noguera, D.R. DECIPHER, a Search-Based Approach to Chimera Identification for 16S RRNA Sequences. Appl. Environ. Microbiol. 2012, 78, 717-725. [CrossRef] [PubMed]

37. Thompson, J.D.; Higgins, D.G.; Gibson, T.J. CLUSTAL W: Improving the Sensitivity of Progressive Multiple Sequence Alignment through Sequence Weighting, Position-Specific Gap Penalties and Weight Matrix Choice. Nucleic Acids Res. 1994, 22, 4673-4680. [CrossRef] [PubMed]

38. Kumar, S.; Stecher, G.; Tamura, K. MEGA7: Molecular Evolutionary Genetics Analysis Version 7.0 for Bigger Datasets. Mol. Biol. Evol. 2016, 33, 1870-1874. [CrossRef] [PubMed]

39. Letunic, I.; Bork, P. Interactive Tree of Life (ITOL): An Online Tool for Phylogenetic Tree Display and Annotation. Bioinformatics 2007, 23, W293-W296. [CrossRef] [PubMed]

40. Carlsson, J.; Yuhas, J.M. Liquid-Overlay Culture of Cellular Spheroids. In Spheroids in Cancer Research; Springer: Berlin/Heidelberg, Germany, 1984; Volume 95, pp. 1-23.

41. Plotly Technologies Inc. Collaborative Data Science. Available online: https:/ /Chart-Studio.Plotly.Com/ (accessed on 18 March 2021).

42. Girão, M.; Ribeiro, I.; Ribeiro, T.; Azevedo, I.C.; Pereira, F.; Urbatzka, R.; Leão, P.N.; Carvalho, M.F. Actinobacteria Isolated from Laminaria Ochroleuca: A Source of New Bioactive Compounds. Front. Microbiol. 2019, 10, 683. [CrossRef]

43. Aron, A.T.; Gentry, E.C.; McPhail, K.L.; Nothias, L.F.; Nothias-Esposito, M.; Bouslimani, A.; Petras, D.; Gauglitz, J.M.; Sikora, N.; Vargas, F.; et al. Reproducible Molecular Networking of Untargeted Mass Spectrometry Data Using GNPS. Nat. Protoc. 2020, 15, 1954-1991. [CrossRef] 